\title{
Research on Architectural Function of Taoping Qiang Village Based on Functionalism
}

\author{
Hongtao Ding \\ College of Urban Planning and Architecture, Southwest Minzu University, Chengdu, China \\ Email: 1483765726@qq.com
}

How to cite this paper: Ding, H.T. (2021)

Research on Architectural Function of Taoping Qiang Village Based on Functionalism. Open Access Library Journal, 8: e7601.

https://doi.org/10.4236/oalib.1107601

Received: May 31, 2021

Accepted: June 27, 2021

Published: June 30, 2021

Copyright $\odot 2021$ by author(s) and Open Access Library Inc.

This work is licensed under the Creative Commons Attribution International License (CC BY 4.0).

http://creativecommons.org/licenses/by/4.0/

\begin{abstract}
The study in ABA prefecture of Sichuan province Gutang peach Qiangzhai as an example, based on the functional of peach Qiangzhai building function of research and exploration, peach Qiangzhai location and complex spatial systems, under the background of new era, the modern society of peach Qiangzhai under the influence of double vision of peach Qiangzhai identity, conclusion and reflection on the influence of the old and new Qiangzhai phenomenon, Carry out comparative studies and put forward their own thinking hypotheses. It is inevitable that Taoping Qiang Village will change in the future. I want to preserve the excellent cultural essence of the Qiang nationality while not sticking to it. It must keep pace with The Times and protect and develop it in the process.
\end{abstract}

\section{Subject Areas \\ Architecture, Culture}

\section{Keywords}

Layout Space, Qiang Architecture, Functionalism, Historical Evolution

\section{Introduction}

Taoping Qiang Village of Li County is located in Taoping Township of Zagunao River in Li County. Qiang Village is 40 kilometers away from the downtown area of Li County [1]. Its relative environment is isolated and well preserved. After the earthquake on May 12, 2008, a comprehensive assessment of the old villages formed a special layout of the new villages and the old villages [2]. At present, Taoping Qiang Village is the world's most complete preserved still inhabited diaolou and residential buildings integrated architectural complex. 
In recent years, with the development of characteristic tourism in ethnic minority areas, the economic structure of the Qiang area is also changing, and the number of people and income of the tertiary industry is growing continuously. Its original architectural space, cannot meet the existing needs, appeared with the traditional cultural heritage conflict [3]. At the same time, scholars' protection will is greater than the self-demand of the village subject, and the protection concept is difficult to be implemented without a clear understanding of the internal obstacles. How the coexistence of old and new stockades can develop harmoniously is one of the emphases of the study. Summarizing the advantages and problems of Taoping Qiang Village can help to avoid detours in the process of rural revitalization in ethnic minority areas.

\section{Historical Changes of Architectural Space in Taoping Qiang Village}

\subsection{The Historical Origin of Taoping Qiang Village}

At the end of the Yangshao Culture, the ancient Qiang tribe was a part of the ancient China. Due to the war, it migrated and merged with the local aboriginal inhabitants, becoming the Han and Qiang ethnic groups of the Han and Tibetan languages. From the perspective of anthropology, the direct reason for the migration of the ancient Qiang people is to escape the war. So I came to the mountains and started my own unique way of life.

Taoping Qiang Village was built for security and defense. It was first built in the Western Han Dynasty. Most of them were built in the Ming and Qing Dynasties. The construction materials are mainly made of earth, stone and wood. The preservation is still a wonder. It is the most complete preservation of Qiang architectural complex in the world. It has a long history in the construction of Qiang Village. Due to the limitation of the mountainous terrain, the entire stockade is built along the mountain, and the overall scale is not large. From the point of origin, we can define this as the basic needs of the Taoping Qiang village at the very beginning, which is the place where the whole ethnic group lives.

\subsection{Analysis of Taoping Qiang Village Site Selection}

The whole Taoping Qiang Village is located on a high mountainside platform with a slight slope at the edge of Zagunao River, a tributary of Minjiang River, close to the spring. From the perspective of topographic topography, the relative elevation difference of the Qiang Village is relatively large. From the perspective of functionalism in anthropology, the site selection of Qiang village was determined for the survival of the whole settlement and in combination with the distribution characteristics of ethnic groups in the region at that time. It determines the safety and guarantee of the future survival of the whole settlement. From the perspective of functionalism in design, the site selection of the Qiang Village in Taoping can be regarded as a geomantic treasure. In the mountainous area with bad natural environment, Taoping Qiang Village can be located near mountains 
and rivers to avoid the damage of general geological disasters. This is the wisdom crystallization of our ancestors.

\section{Architectural Functional Characteristics of Taoping Qiang Village}

\subsection{Taoping Qiang Village Architecture}

Through the precipitation of history, Qiang village has formed such unique regional architectural cultures as Qiang blockhouse defense culture, white stone religious culture, cattle and sheep wealth culture (Figure 1), and stone construction culture, which make its residential buildings with distinctive features. Taoping Qiang village buildings are built by hand with soil and pieces of stone by digging holes to put up wood and setting up columns against walls [4]. The whole village is integrated at one go and is a representative of stone blockhouses in Qiang area. The underground water supply system in Taoping Qiang village is the most mature and representative water system in Qiang region. It has the function of defense, fire fighting and "natural air conditioning". The unique three-layer transportation network of roof, street and underground water network in Taoping Qiang village constitutes its unique military defense system and three-dimensional transportation network. Taoping Qiang Village has a strong "centripetal force", which is a typical "point" type of aggregation [5]. The Qiang

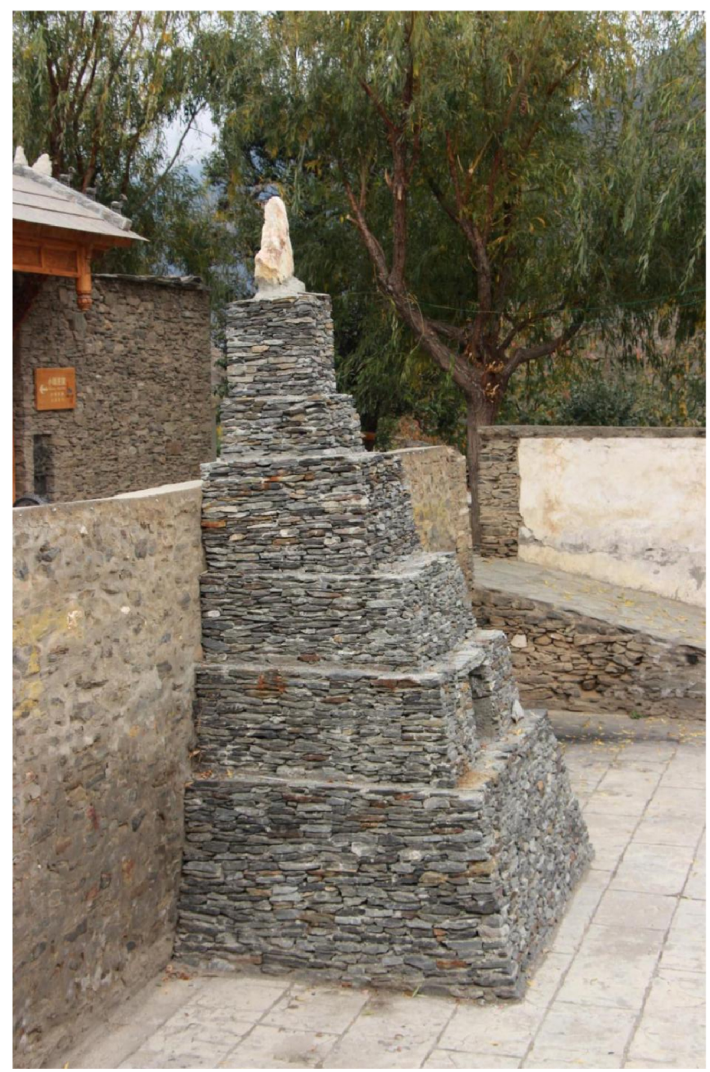

Figure 1. Taoping qiang white stone (Photo by the author). 
houses are terraces in the shape of stairs, with a random defensive function of "cohesion" and a varied layout.

\subsection{Spatial System of Taoping Qiang Village}

From the perspective of anthropology, the entire layout of Taoping Qiang Village is like the structure of human body. The ground road network and underground water network are as connected as human blood vessels, connecting the whole and the part (Figure 2). The overall structure of Qiang Village is interdependent, with every household and every house being interdependent and interconnected. Then, we can analyze that this is because it is located in the high mountainside platform, available construction land is less; The other is to protect against foreign invasion and ensure unimpeded communication in time of war. In the construction activities of the living environment, the Qiang people show a strong demand for security and a sense of territory. This demand is manifested in the settlement, where people live in groups in time and cooperate for defense. Therefore, every settlement has a pillbox for collective defense. It is reflected in the single residential dwellings. The walls are high and closed, the window openings are narrow, easy to defend and difficult to attack, and there are also diaolou for family defense. In the modern society, the original architectural functions of Qiang village have been changed based on their own needs, and the functions of the new village have been diversified.

\subsection{Function Changes of Taoping Qiang Village after the Earthquake}

Since the 5.12 Wenchuan earthquake, the earthquake has not only brought losses but also promoted the upgrading of Qiang people's dwellings. Compared with the plain area and the eastern coastal area, the development of rural areas in

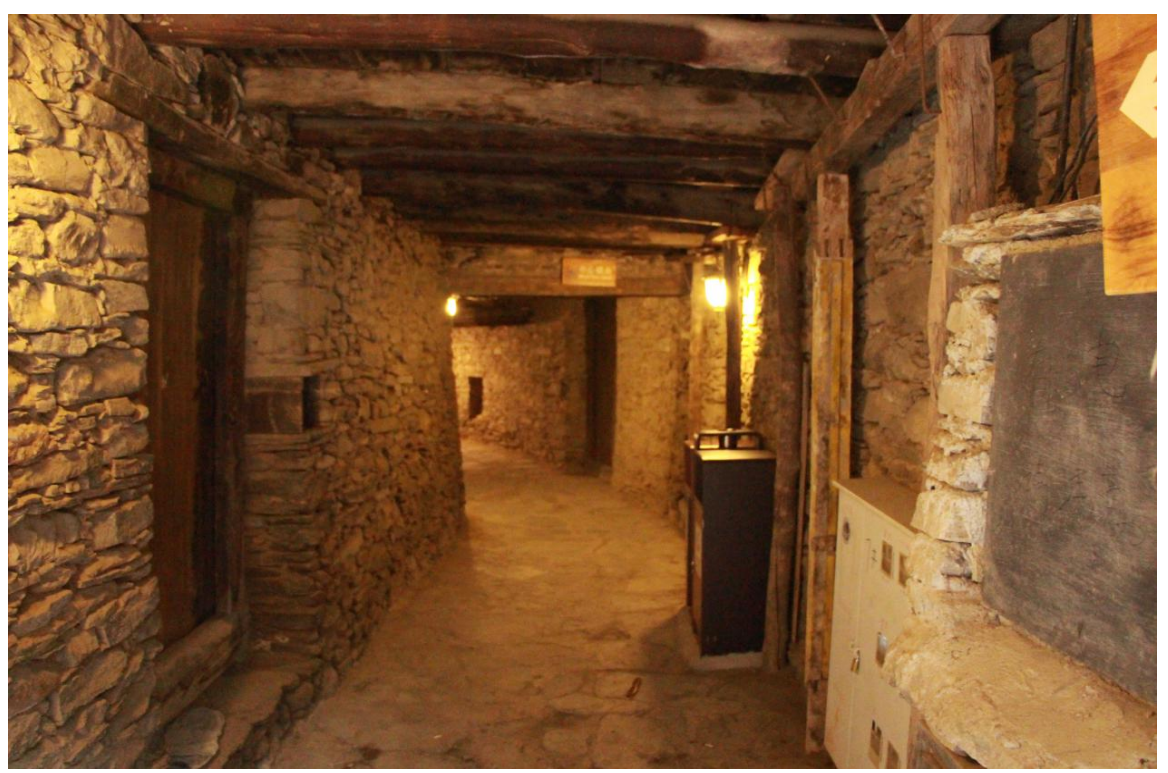

Figure 2. Ground road network of taoping qiang village (Photo by the author). 
Qiang nationality area is lagging behind and passive. Forestry and agriculture are still the main economic sources and production modes, and the dominant position of agriculture and forestry has not changed substantially. But in recent years, with the development of characteristic tourism in ethnic minority areas, the economic structure of the Qiang region is also changing, and the number and income of the tertiary industry are growing continuously. Modern agricultural production and rural life style have brought new opportunities for rural development in the Qiang region, which will present a new development trend. The rural appearance of the Qiang region has also been improved, and the living form is different from the traditional folk houses and urban houses, showing new characteristics.

The 5.12 earthquake caused serious damage to Taoping Qiang folk houses, which was based on the value of the buildings and the damage degree in the earthquake [3]. In the reconstruction planning, the concept of "landscape dwelling" was put forward creatively to realize living protection for Taoping Qiang Village, so as to ensure the simultaneous participation of residents and protection planning and realize the dynamic inheritance of Taoping Qiang Village culture. Planning in accordance with the three-level planning. In the post-earthquake planning and design, the landscape effect of planting trees should be adjusted according to the landscape conditions, so as to achieve the unity of ecology, economy and landscape. The overall positioning is to develop the Qiang cultural tourism industry as a national historical and cultural village with the folk customs of the Qiang. With "revitalizing the stock and controlling the increment" as the guiding core of development, with the migration of Qiang people as the main element, with the renewal of business forms as the main way, and taking into account the research and development of tourism products, the transformation from special products to high-quality products to rare products has been gradually realized. The infrastructure of the new village has been improved and the infrastructure of the old village has been improved. After the earthquake, Taoping Qiang's economy has undergone a transformation, and its functions have changed from living and production to tourism and culture.

\section{The Influence of Modern Lifestyle on Taoping Qiang Village}

The feudal chieftain system applied in the Qiang region before the liberation, and the administrative jurisdiction of the Qiang region after the liberation. After several changes, from 1953 to 1987, experienced several changes. Eventually Aba Prefecture was renamed Aba Tibetan and Qiang Autonomous Prefecture. Due to the fundamental changes have taken place in the political system, bring the great development of economy, the peaceful environment makes the traditional qiang villages of national defense and defensive lost the social foundation of the existence of, can also open more big qiang folk houses, shot mouth also is no longer needed, qiang bleaching no longer has the military defense value and become the regional residential a symbolic symbols (Figure 3). 


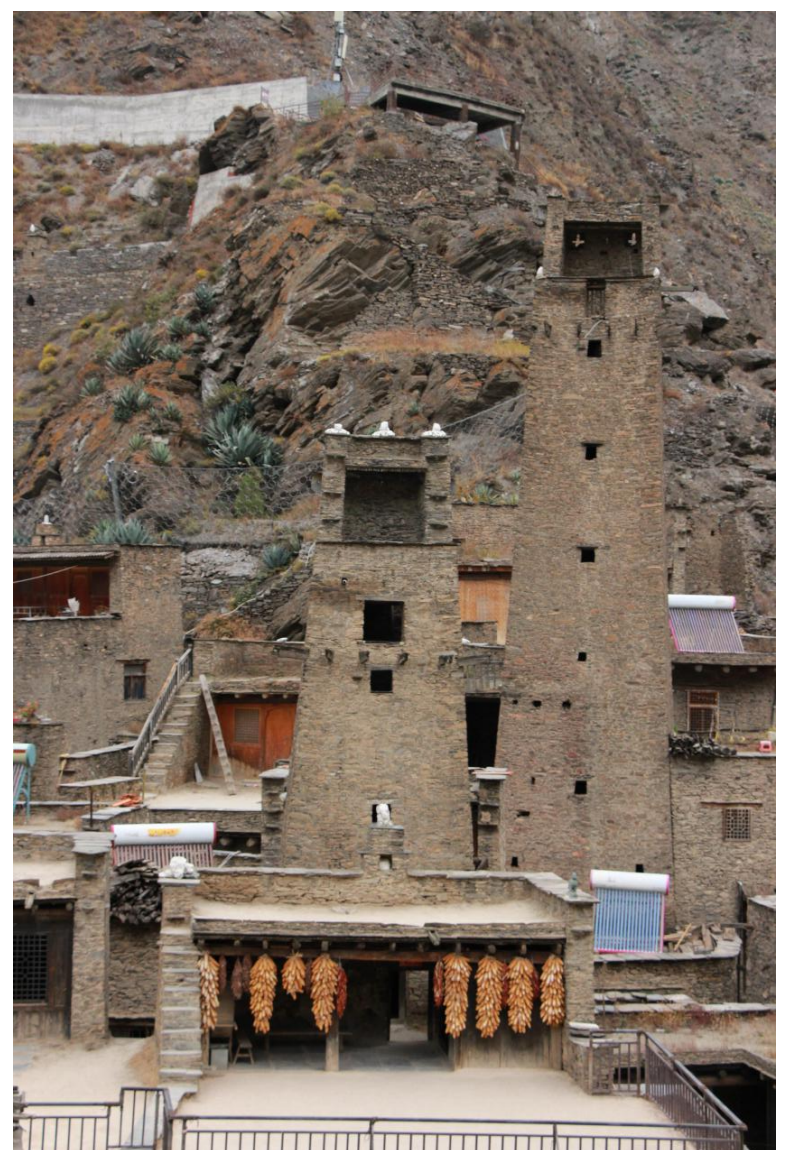

Figure 3. Diaolou of taoping qiang village (Photo by the author).

Due to peach QiangZhai belongs to the seismic intensity big, steep slope, the surface broken, earthquake, mud-rock flows, landslides and floods are common in the region, see more of the disaster, under the influence of the objective conditions, some working or financially wealthy family, moved away from here, make the settlement of population loss, thus lost the population base. As a result, the integrity and vitality of Taoping Qiang settlement culture are reduced. When the modern way of life did not enter the Qiang area, the characteristics of settlement were in groups, and the phenomenon of population loss was almost non-existent. The modern way of life in Qiang has changed this balance. Its unique clustering characteristics also lost its original significance.

Traditional QiangZhai settlements, with a family history of management, with its collective defense, surrounding the officer for the village or cuddled up build diaolou, present the beauty of the harmonious mountain settlements, liberation and implemented cooperatives, reform and opening up people production quotas, the original gathered, introverted pattern has been broken, private land consciousness is strong, respectively for the phenomenon is common, to build house for near the road Instead of building around the diaolou or old houses in the village, the Qiang villages are undergoing an all-round change at three levels, i.e. point, line and plane, to meet the needs of modern life. As a result, the public 
space of the village collapsed and people did not need to build huge buildings of diaolou. Due to the increased demand for vehicles (Figure 4), the subsequent reconstruction of the traffic road linear structure overturns the original village organizational relationship. From the perspective of anthropology, the integrity of Qiang village has been broken, and its functions have been diversified.

\section{How Will the Function of Taoping Qiang Village Change in the Future}

Taoping Qiang Village has existed for thousands of years. From the perspective of social development, its functions have changed slowly, mainly after the founding of New China. Relatively speaking, with the impact of modern culture and mode of production, cultural assimilation is almost inevitable. The advanced cultural law always comes into contact with the relatively weak and backward culture and the relatively strong, advanced and perfect culture. Now the Qiang people are in the process of continuous cultural integration and development. In the evolution of modern Qiang folk houses, cultural assimilation is an objective reality, which also leads to the loss of the modeling elements of folk houses.

Therefore, the architectural space will inevitably change accordingly. For example, the distinctive national modeling elements such as the Diaolou, the Enclosed Tower, the Street Building, and the Panglou are gradually disappearing. Due to the pragmatic cultural view, the Qiang ethnic style components are missing. There are many shapes and modeling elements with regional and national characteristics in Qiang people's forms [6]. Cover floor lose real function and become a redundant components, choose floor now evolved into the balcony, at present still have the function of significance, but the bridge gallery for street widening roads and traffic needs gradually disappear, the form elements disappear gradually, makes the modern qiang folk house style and profound

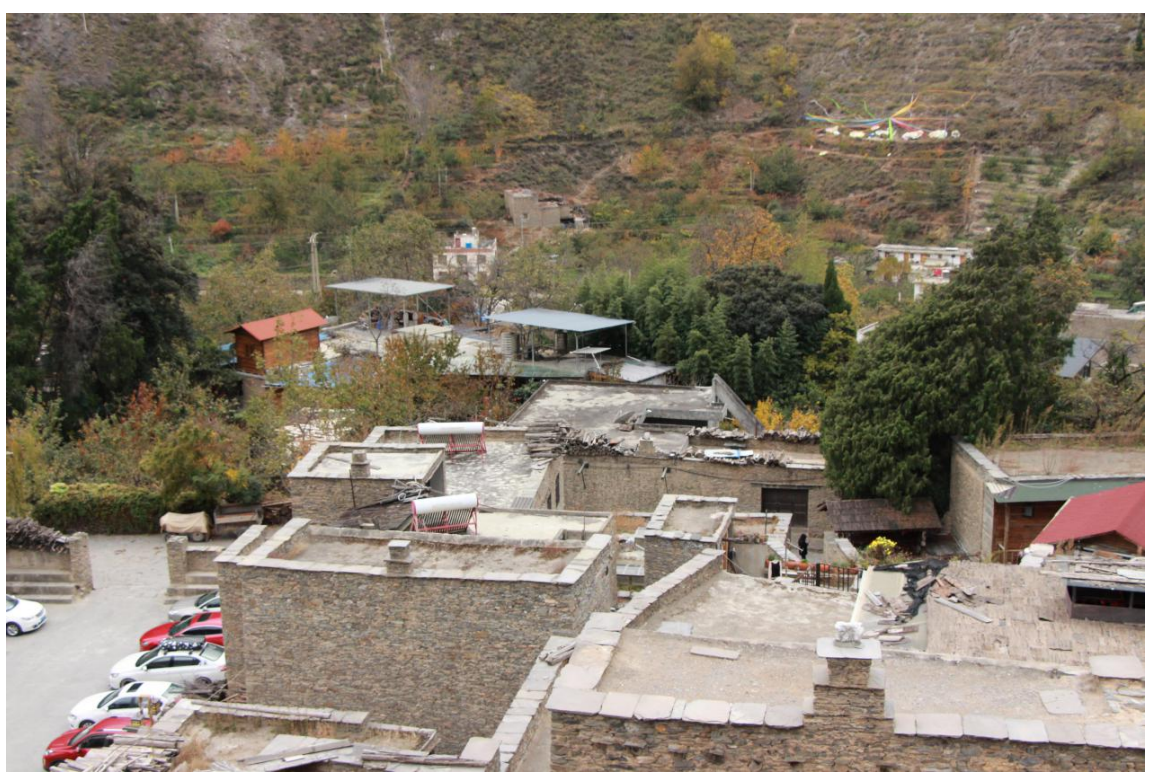

Figure 4. Taoping qiang village parking park (Photo by the author). 


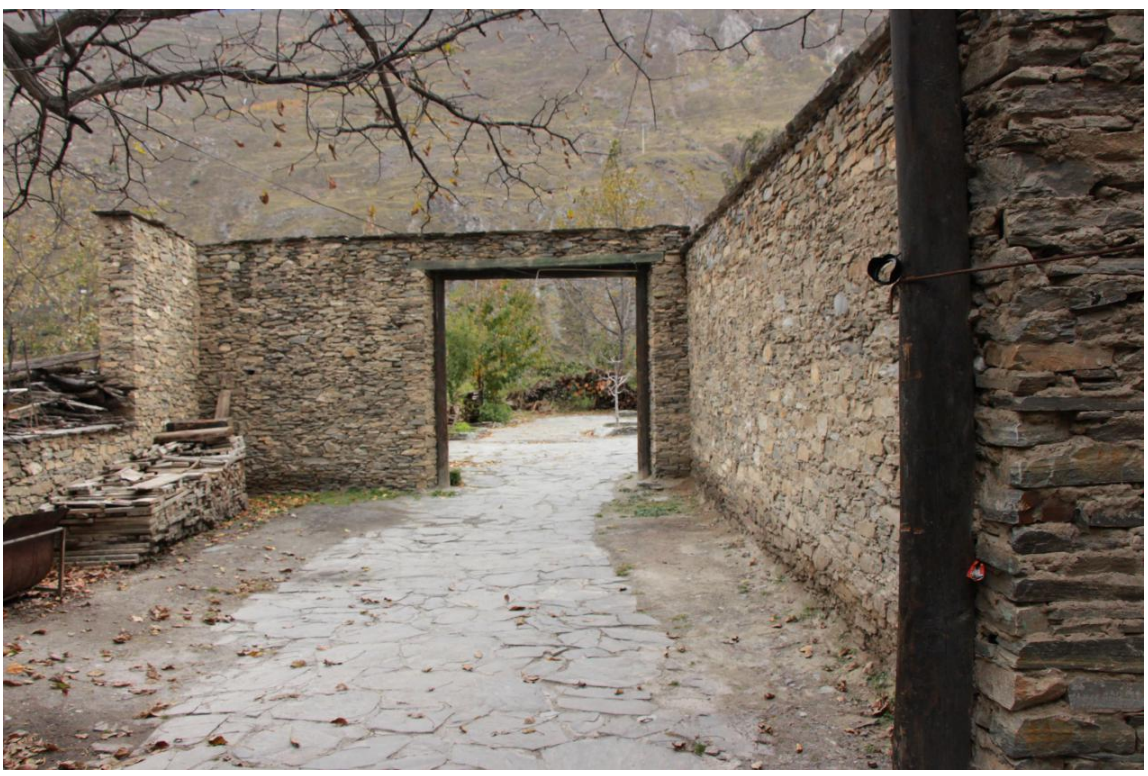

Figure 5. Taoping qiang village road (Photo by the author).

changes, appeared the tendency of homogeneity, cookie-cutter houses become a common phenomenon, be badly in need of Learn to improve, reasonable choice, inherit the body of the scientific part, such as cover building drive ventilation, can be re-recognized and utilized. Figure 5 shows a road of Taoping Qiang Village.

The transformation of the mode of production is irreversible. The new urbanization has been fully realized, and the traditional pattern cannot meet the current needs [4]. In Moutuo village of Maoxian county, there is a separate pig farm, and there is a stripping of the production houses in the folk dwellings, such as the construction of mushroom production houses alone. It is inevitable that Taoping Qiang Village will change in the future. I want to preserve the excellent cultural essence of the Qiang nationality while not sticking to it. It must keep pace with The Times and protect and develop it in the process.

\section{Conclusion}

The research and analysis of architectural functions of Taoping Qiang village based on functionalism mainly aim to explore the culture and design characteristics of Taoping Qiang village from the perspective of functionalism in anthropology and design, and to tentatively imagine the future development.

\section{Conflicts of Interest}

The author declares no conflicts of interest regarding the publication of this paper.

\section{Funding}

This paper is supported by Southwest Minzu University's Innovative Research 
Project for Postgraduates in 2021 (No. CX2021SP157).

\section{References}

[1] Li, F. (2020) Technical Discussion on the Compilation of the Protection and Development Planning of Traditional Villages-Planning Practice of Taoping Village in Li County, Aba Tibetan and Qiang Autonomous Prefecture. Architecture and Decoration, 16, 60-61.

[2] Sun, X.T., Peng, H.B. and Chen, J. (2018) The Characteristics and Stability of Traditinal Qiang Residential Buildings: A Case of Qiang Village in Taoping County of Sichuan. Sichuan University of Arts and Science Journal, 28, 136-141.

[3] Sun, J.X. (2017) Traditional Villages: Theoretical Connotation and Development Path. Tourism Tribune, 32, 1-3.

[4] Xiong, X.Y. and Yu, S.J. (2012) Investigation and Analysis of the Structural System and Damages of Diaofang in Taoping. Sichuan Building Science, 38, 77-80.

[5] Long, H.H., Fu, H., Le, G.C., et al. (2020) A GIS-Based Research on Site Selection and Layout of Tranditional Villages of the Qiang Ethnic Minority before and after the Wenchuan Earthquake. Chongqing Architecture, 19, 10-13.

[6] Feng, F.P. and Wei, Q.H. (2020) Industrial Policy, Scientific and Technological Human Resource Allocation and Enterprise Innovation Risk. Review of Investment Studies, 39, 142-157. 